\title{
Extraction of cadmium from phosphoric acid by a synthesized extracting agent
}

\author{
Kaoutar Berkalou, ${ }^{1, *}$, Abderrahman Nounah ${ }^{1}$, Mohamed Khamar ${ }^{1}$, Ratiba Boussen $^{2}$ and Essediya Cherkaoui ${ }^{1}$ \\ ${ }^{1}$ Civil Engineering and Environment Laboratory (LGCE). Materials Water and Environment team, High School of Technology, Sale, \\ Morocco \\ ${ }^{2}$ Laboratory of Nanotechnology Materials and Environment Mohammed V University; Faculty of Sciences, Rabat, Morocco
}

\begin{abstract}
The Purification of phosphoric acid used several extractants from the family of oxygenates, sulfurous or amino compounds. In this work, we were interested in the synthesis, physico-chemical and spectroscopic characterization, and use of the product $\mathrm{C}_{11} \mathrm{H}_{18} \mathrm{~N}_{2} \mathrm{O}$ as an extractant of cadmium from phosphoric acid. The synthesized product was characterized by: infrared spectroscopy, nuclear magnetic resonance, and mass spectroscopy. Solubility tests in different solvents have been carried out. Subsequently, liquid-liquid extraction of cadmium from phosphoric acid was carried out using $\mathrm{C}_{11} \mathrm{H}_{18} \mathrm{~N}_{2} \mathrm{O}$ as an extractant diluted in benzene. The study investigated the influence of concentration of phosphoric acid and the extracting agent. The result obtained ensure that our synthesized product is promising. The percentage of cadmium extraction from phosphoric acid reached $98.58 \%$ at a concentration of $2.5 \mathrm{M}$ phosphoric acid and an optimal concentration of $0.5 \times 10^{-2} \mathrm{M}$ of synthesized extractant.
\end{abstract}

\section{Introduction}

Phosphoric acid is a basic intermediate compound in sensitive industrial fields such as; pharmaceuticals, food, detergents and fertilizers. $\mathrm{H} 3 \mathrm{PO} 4$ is mainly manufactured by wet process, where phosphates are solubilized by mineral acids, which often gives a product contaminated with several heavy metals. Several methods were evaluated for the purification of phosphoric acid from heavy metals and in particular the removal of cadmium by liquid-liquid extraction by different extracting agents. Almela [1] was able to extract up to $90 \%$ of the $\mathrm{Cd}(\mathrm{II})$ from phosphoric acid with the commercial product bis (2,4,4-trimethylpentyl) thiophosphinic acid (cyanex 302) diluted in kerosene. Kherfan [2] pointed out that the extraction of cadmium from phosphoric acid could be performed with the solvent TOPO (trioctyl phosphine oxide) diluted in kerosene. Elyahyaoui [3] verified that DHEHP remains the best extractant of cadmium from phosphoric acid, comparing it either by tributylphosphate (TBP), trioctyl phosphine oxide (TOPO), triphenyl phosphine oxide (TPPO), or diphenylamine used individually or mixed. Nazari [4] studied the extraction of industrial phosphoric acid from the wet process (WPA), using the Alamine 336 as extracting agent that represent a mixture of : trin-octylamine, trin-decylamine, TBP, D2EHPA, and TOPO diluted in 1,2,4-trimethylbenzene/kérosène with the addition of iso-dodecanol in the organic phase. The extraction yield of cadmium from phosphoric acid reached is $68.57 \%$ after 20 cycles of the organic phase.
The extractant 7-(4-ethyl-1-methyloctyl) -8hydroxyquinoline tested by Mellah [5] diluted in kerosene for the extraction of zinc, copper and cadmium from $5.5 \mathrm{M}$ phosphoric acid. A recovery of $60 \%$ of the metals was obtained. Mellah [6] in other work used the di-2-ethyl hexyl phosphoric acid (D2HDPA) extractant diluted in kerosene for the extraction of cadmium and zinc from phosphoric acid. Touati [7] examined D2HDTPA as an extractant diluted in dodecane, and showed a high affinity for $\mathrm{Cd}(\mathrm{II})$ in a phosphoric acid solution with an extraction percentage of $99.1 \%$. Recently, Senhaji $[8,9]$ used an extractant with bifunctional sulfur groups (C9H8N2S) for the extraction of cadmium from phosphoric acid. On our part, we have opted for the synthesis of an oxygenated product $(\mathrm{C} 11 \mathrm{H} 18 \mathrm{~N} 2 \mathrm{O})$ to use it as an extractant cadmium from phosphoric acid.

\section{Materials \& methods}

Our extracting agent is synthesized by a mixture of a urea solution, in a Hydrochloric acid medium, and pulegone under magnetic agitation for 48 hours at room temperature. After evaporation of about $3 / 4$ of the ethanol, the precipitate formed is filtered, and then washed with water. The resulting solid is purified by recrystallization in acetone. The product $\mathrm{C}_{11} \mathrm{H}_{18} \mathrm{~N}_{2} \mathrm{O}$ is obtained with a yield of $51 \%[10,11]$.

To characterize our synthesized product we used: infrared spectroscopy (Bruker,VERTEX70,MIR transmission), nuclear magnetic resonance (AVANCE I

Corresponding author: kaoutar.berkalou@gmail.com 
(Bruker),300MHZ,7.05 Tesla), and mass spectroscopy (Q-TRAP,ESI,APCI) . For the melting point we have used the G. BOYER device. Solubility has been tested in different solvents: Toluene, Chloroform, Dichloromethane, Diethyl ether, Benzene analytical grade (Riedel-de hën).

The different phosphoric acid solutions 1 to $5.5 \mathrm{M}$ were prepared from phosphoric acid of $85 \%$ (VWR CHEMICALS). Cadmium is used at a concentration of $10^{-3} \mathrm{~mol} / 1$ in the form of cadmium hydroxide $\left(\mathrm{Cd}(\mathrm{OH})_{2}\right)$. The organic phases are prepared by dissolving three quantities of the synthesized extractant $\left(\mathrm{C}_{11} \mathrm{H}_{18} \mathrm{~N}_{2} \mathrm{O}\right)$ : $0.5 \times 10^{-2} \mathrm{M}, 1 \times 10^{-2} \mathrm{M}, 1.5 \times 10^{-2} \mathrm{M}$ in benzene $\left(\mathrm{C}_{6} \mathrm{H}_{6}\right)$. All reagents were of analytical quality and used without further purification. The various extraction experiments were carried out in a beaker (compromising $5 \mathrm{ml}$ of the aqueous phase and $5 \mathrm{ml}$ of the organic phase) magnetically stirred at a stirring of about $800 \mathrm{rpm}$ at room temperature $20^{\circ} \mathrm{C}$ (modèle VWR incubating Mini Shaker). After stirring, the aqueous phase and the organic phase were separated. Cadmium concentrations were determined in the aqueous phase by inductively couples plasma spectrometry (ICP-OES PerkinElmer Optima 8000).

\section{Results and discussions}

\subsection{Characterization of the extracting agent}

\subsubsection{Infrared spectroscopy (IR)}

As shown in the spectrum in Fig. 1, we note by using Table 1:

- Between 3200 and $3500 \mathrm{~cm}^{-1}$, the elongation vibration of N-H bond are mainly found. More precisely, the following frequencies are attributed to the vibration modes: $3240 \mathrm{~cm}^{-1}$ et $3415 \mathrm{~cm}^{-1}$.
- Between 2690 and $3100 \mathrm{~cm}-1$ the elongation vibrations in $\mathrm{C}-\mathrm{H}$ bands, also an elongation vibration is around $1400 \mathrm{~cm}^{-1}$.

- At $1687 \mathrm{~cm}^{-1}$, an elongation vibration of $\mathrm{C}=\mathrm{O}$.

- At $1488 \mathrm{~cm}-1$, we observe the elongation band of $\mathrm{C}=$ $\mathrm{C}$ at low intensity.

- At $1448 \mathrm{~cm}^{-1}$, a deformation of $\mathrm{CH}_{2} \& \mathrm{CH}_{3}$ bond in the case of alkanes.

- At $1209 \mathrm{~cm}^{-1}$, an average elongation of C-N bond in the case of amines.

Table 1. Different functional classes with their attributions.

\begin{tabular}{|c|c|c|c|}
\hline Functional classes & $\begin{array}{c}\text { Number } \\
\text { of waves } \\
\left(\mathrm{cm}^{-1}\right)\end{array}$ & Intensity & Attribution \\
\hline $\begin{array}{c}\text { Carboxylic acids \& } \\
\text { derivatives } \\
\text { (elongation } \\
\text { vibrations) }\end{array}$ & $\begin{array}{c}1630- \\
1695 \\
\text { (amides) }\end{array}$ & Strong & $\begin{array}{c}\mathrm{C}=\mathrm{O} \text { (amide } \mathrm{I} \\
\text { band) }\end{array}$ \\
\hline $\begin{array}{c}\text { Aldehydes \& } \\
\text { ketones (elongation } \\
\text { vibrations) } \\
\end{array}$ & $\begin{array}{l}2690- \\
2840\end{array}$ & Average & $\begin{array}{l}\mathrm{C}-\mathrm{H}(\mathrm{C}-\mathrm{H} \\
\text { aldehyde })\end{array}$ \\
\hline $\begin{array}{l}\text { Arenas (elongation } \\
\text { vibrations) }\end{array}$ & 3030 & Variable & $\begin{array}{l}\text { C-H (it can } \\
\text { be several } \\
\text { bands) }\end{array}$ \\
\hline $\begin{array}{l}\text { Alkynes (elongation } \\
\text { vibrations) }\end{array}$ & 3300 & Strong & $\begin{array}{c}\text { C-H } \\
\text { (generally } \\
\text { fine) }\end{array}$ \\
\hline $\begin{array}{l}\text { Arenas (elongation } \\
\text { vibrations) }\end{array}$ & $\begin{array}{c}1600 \& \\
1500\end{array}$ & $\begin{array}{l}\text { Medium- } \\
\text { low }\end{array}$ & $\begin{array}{c}\mathrm{C}=\mathrm{C} \text { (in a } \\
\text { cycle) }(2 \\
\text { bands, } 3 \text { if } \\
\text { conjugated })\end{array}$ \\
\hline $\begin{array}{l}\text { Amines (elongation } \\
\text { vibrations) }\end{array}$ & $\begin{array}{c}3050- \\
3500\end{array}$ & $\begin{array}{l}\text { Strong } \\
\text { band }\end{array}$ & $\mathrm{N}-\mathrm{H}$ \\
\hline $\begin{array}{l}\text { Amines (elongation } \\
\text { vibrations) }\end{array}$ & $\begin{array}{c}1000- \\
1250\end{array}$ & Average & $\mathrm{C}-\mathrm{N}$ \\
\hline $\begin{array}{c}\text { Alkanes (elongation } \\
\text { vibrations) }\end{array}$ & $\begin{array}{l}1350- \\
1470\end{array}$ & Average & $\begin{array}{l}\mathrm{CH}_{2} \& \mathrm{CH}_{3} \\
\text { deformation }\end{array}$ \\
\hline
\end{tabular}

CNRST - RABAT

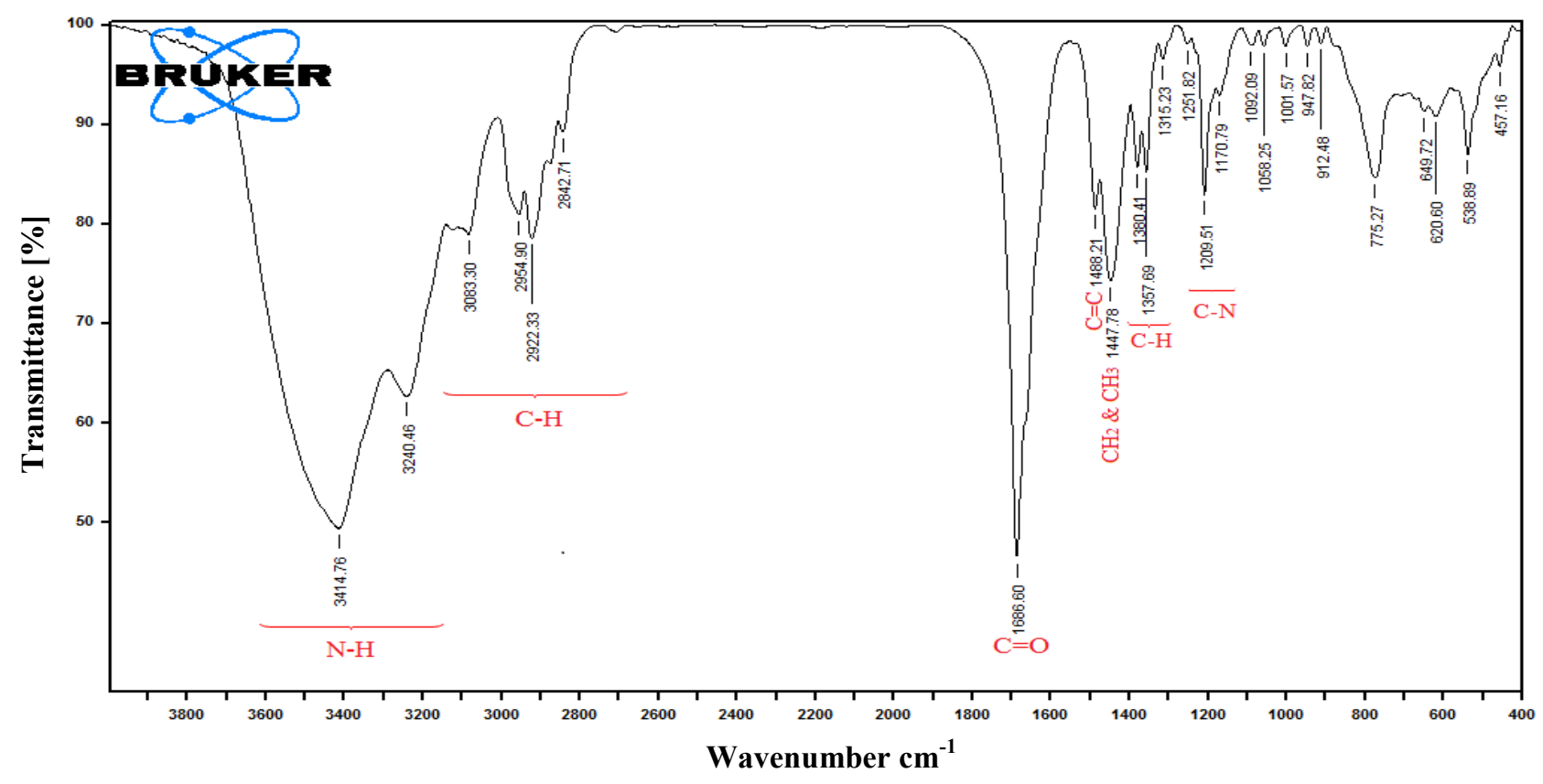

Fig. 1. Infrared analysis spectrum of extractant agent $\left(\mathrm{C}_{11} \mathrm{H}_{18} \mathrm{~N}_{2} \mathrm{O}\right)$. 
The presence of these peaks in this domain strongly suggests the presence of the characteristic bonds ( $\mathrm{NH}, \mathrm{C}=\mathrm{O}, \mathrm{CH}, \mathrm{C}=\mathrm{C}, \mathrm{CH}_{2}, \mathrm{CH}_{3}, \mathrm{CN}$ ) of our synthetic product $\mathrm{C}_{11} \mathrm{H}_{18} \mathrm{~N}_{2} \mathrm{O}$.

\subsubsection{Nuclear magnetic resonance (RMN)}

The nuclear magnetic resonance identifying the synthesized product is given as follows:

\section{RMN ${ }^{1} \mathbf{H}$ (300 MHz):}

$\begin{array}{llcll}7.84 & \text { ppm } & \text { s } & 1 \mathrm{H} & \mathrm{H}_{1} \\ 6.50 & ---- & \text { s } & 1 \mathrm{H} & \mathrm{H}_{3} \\ 1.55-1.94 & ---- & \mathrm{m} & 6 \mathrm{H} & \mathrm{H}_{5,6,8} \\ 1.14 & ---- & \mathrm{s} & 6 \mathrm{H} & \mathrm{H}_{10,10} \\ 0.93 & --- & \mathrm{d} & 3 \mathrm{H} & \mathrm{H}_{9} \\ 2.51-2.52 & ---- & \mathrm{m} & 1 \mathrm{H} & \mathrm{H}_{7}\end{array}$

The results found by nuclear magnetic resonance corresponds to our synthesized product.

\subsubsection{Mass spectroscopy}

Based on the mass spectrum (Fig. 2), a molecular weight of 195 corresponding to the RH from our synthetic product $\mathrm{C}_{11} \mathrm{H}_{18} \mathrm{~N}_{2} \mathrm{O}$ was obtained.

\subsubsection{The melting point}

Using the G.BOYER measuring instrument, it was found that the melting point of the synthetic product $\mathrm{C}_{11} \mathrm{H}_{18} \mathrm{~N}_{2} \mathrm{O}$ varies from $139-140$, a close value was found by Tabouazat [11].

\subsection{Extraction of cadmium from phosphoric acid}

In order to verify the efficacy of our synthetic product as extracting agent extractant in acidic medium, we tested concentrations of $\mathrm{C}_{11} \mathrm{H}_{18} \mathrm{~N}_{2} \mathrm{O}: 0.5 \times 10^{-2} \mathrm{M}, 1 \times 10^{-2} \mathrm{M}$, $1.5 \times 10^{-2} \mathrm{M}$ diluted in benzene $\left(\mathrm{C}_{6} \mathrm{H}_{6}\right)$ as the organic phase. Different concentration of phosphoric acid (ranging from $1 \mathrm{M}$ to $5.5 \mathrm{M}$ ) were used in the aqueous phase with a concentration of $10^{-3} \mathrm{M}$ for cadmium. The evolution of the extraction is shown in the Fig. 3.

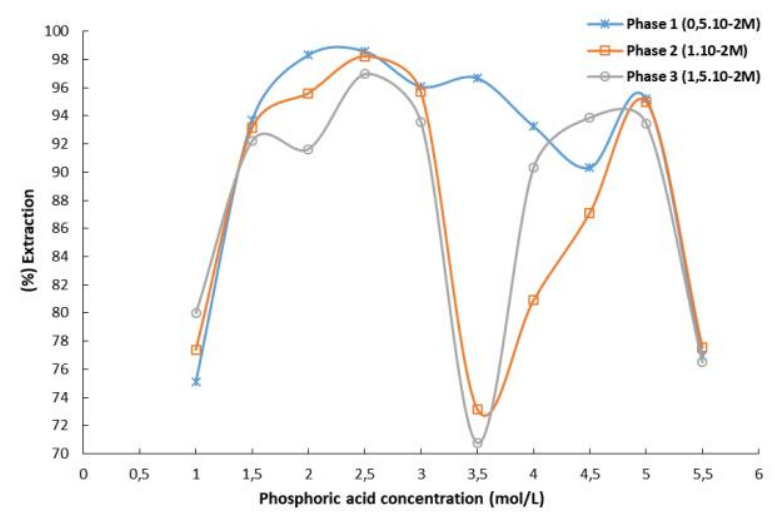

Fig. 2. Effect of the concentration of the extracting agent on the percentage of cadmium extracted from phosphoric acid from 1 to $5.5 \mathrm{M}\left(\left[\mathrm{Cd}^{+2}\right]=10^{-3} \mathrm{M}, \mathrm{T}=20^{\circ} \mathrm{C}\right.$ and stirring time $=$ $90 \mathrm{~min})$

The different curves show a non-uniform evolution for the extraction of cadmium from phosphoric acid ranging from 1 to $5.5 \mathrm{M}$. this is due to the complexity of the form of cadmium present in these media.

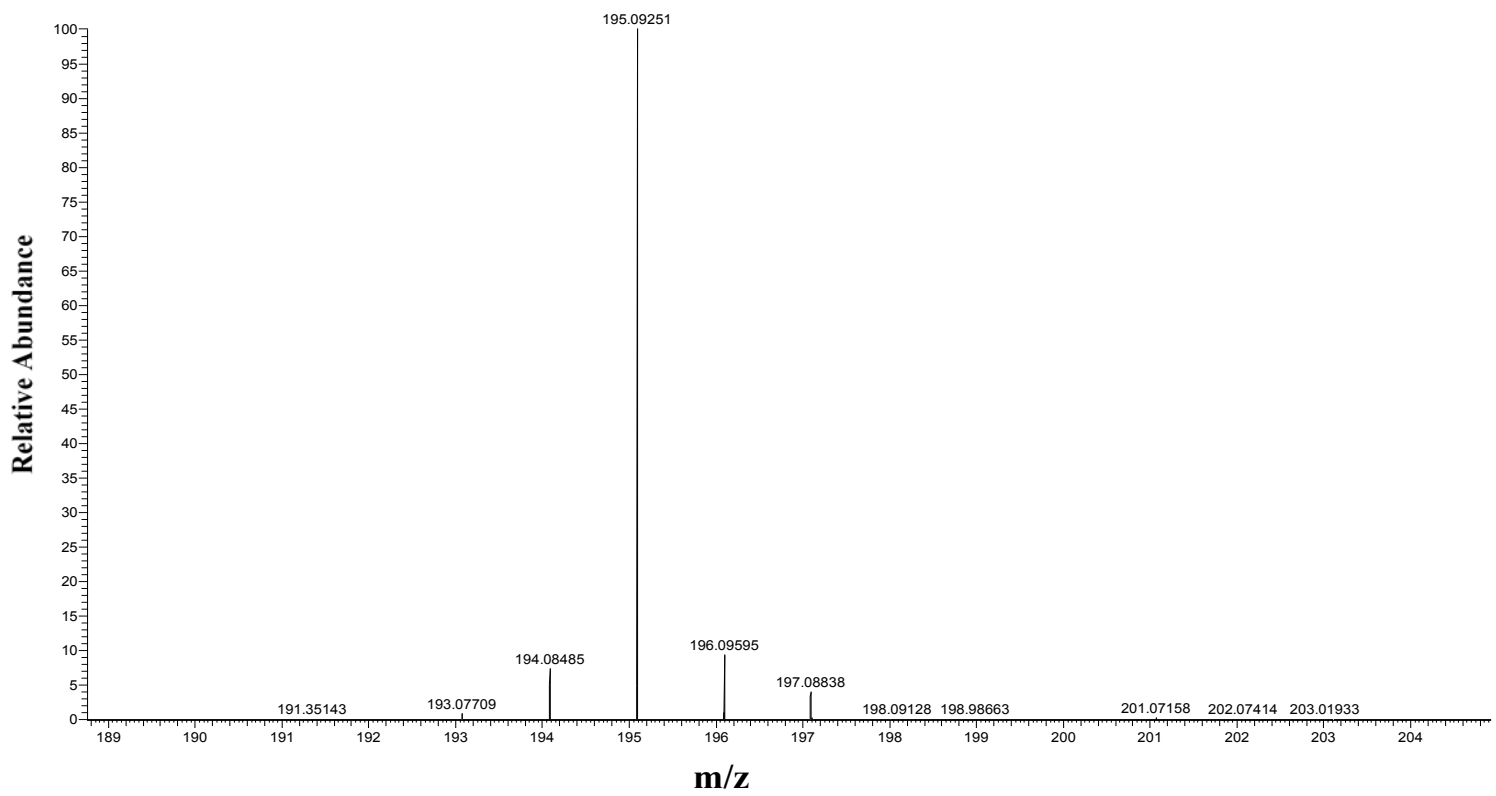

Fig. 2. Extracting agent mass analysis spectrum $\left(\mathrm{C}_{11} \mathrm{H}_{18} \mathrm{~N}_{2} \mathrm{O}\right)$ 
Based on these results (Fig. 3), the highest percentage of cadmium extraction $(98.58 \%)$ corresponding to the concentration $0.5 \times 10^{-2} \mathrm{M}$ of the extractant $\left(\mathrm{C}_{11} \mathrm{H}_{18} \mathrm{~N}_{2} \mathrm{O}\right)$ and the concentration $2.5 \mathrm{M}$ of phosphoric acid.

\section{Conclusion}

The synthesized product has been well identified by the different spectroscopic analysis methods. Its use for the extraction of cadmium from phosphoric acid has proven to be a good extracting agent.

The results can be summarized as follows:

- No third phase was observed under the conditions studied.

- An extraction percentage that varies between $70.77 \%$ and $98.58 \%$ depending on the concentration of phosphoric acid and extracting agent $\left(\mathrm{C}_{11} \mathrm{H}_{18} \mathrm{~N}_{2} \mathrm{O}\right)$.

- This extracting agent is more promising at a phosphoric acid concentration of about $2,5 \mathrm{M}$ and for an optimal concentration of $0.5 \times 10^{-2} \mathrm{M}$ where the extraction of cadmium from phosphoric acid could reach $98.58 \%$.

More advanced studies are the subject of future work.

\section{References}

1. A. Almela, MP. Elizalde, JM. Gómez. Fluid Phase Equilibria 145, 301- 10 (1998)

2. S. Kherfan. Period Polytech Chem Eng 55, 45 (2011)

3. A. Elyahyaoui, S. Bouhlassa. Appl Radiat Isot 54, 921- 6 (2001)

4. K. Nazari, A. Ghadiri, H. Babaie. Miner Eng 18 , 1233- 8 (2005)

5. A. Mellah, D. Benachour. Hydrometallurgy 81, 100 103 (2006)

6. A. Mellah. and D. Benachour. Chem Eng and Processing: Process Intensification 45, 684-690 (2006)

7. M. Touati, M. Enna-Zayani, N. Kbir-Ariguib, M. Trabelsi-Ayadi, A. Buch, JL. Hydrometallurgy 95, 135-140 (2009)

8. S. Senhaji, A. Elyahyaoui, S. Boulassa, E.M. Essassi. Oriental Journal of Chemistry 32, 3035-3041 (2016).

9. S. Senhaji, A. Elyahyaoui, S. Boulassa, E. M. Essassi. (2016)

10. M. Tabouazat, A.E. Louzi, M. Ahmar, B. Cazes. Synlett, 2495-2499 (2008)

11. M. Tabouazat. 1, (2008) 